\title{
Comparison between humans and animal diagnosed with metabolic syndrome and obesity associated metabolic problems
}

\section{Aspecte comparative la om şi animal în diagnosticul sindromului metabolic şi disfuncţiei metabolice asociate obezităţii}

\author{
Ana Maria Alexandra STĂNESCU ${ }^{1}$, Ana Maria GOANȚ̆ ${ }^{2}$, Roxana IGNĂTESCU², \\ Ekua Asafoaba APPIAH ${ }^{1}$, loana Veronica GRĂJDEANU ${ }^{1}$, Lucian IONIȚĂ² \\ ${ }^{1}$ Universitatea de Medicină şi Farmacie „Carol Davila“, Bucureşti, România \\ ${ }^{2}$ Facultatea de Medicină Veterinară, Bucureşti, România
}

\begin{abstract}
Metabolic syndrome is an increasingly recognised problem worldwide. The diagnostic criteria may vary from country to country and between humans and animals. It is therefore essential to have a globally regulated diagnostic criteria for both animals and humans.
\end{abstract}

Keywords: metabolic syndrome, obesity, human, dog, skin disorder

$\left(\begin{array}{l}\text { REZUMAT } \\ \text { Sindromul metabolic capătă proporții la nivel mondial. Criteriile de diagnostic pot diferi în functie de țară } \\ \text { (la om) și în funcție de specie (la animal). Există o necesitate la nivel global de a reglementa criteriile de dia- } \\ \text { gnostic ale sindromului metabolic }\end{array}\right.$

Cuvinte cheie: sindrom metabolic, obezitate, om, câine, afectare cutanată

În medicina umană, sindromul metabolic (SM) a devenit un subiect de interes în ultimii ani, prin asocierea cu diabetul zaharat de tip II și cu bolile cardiovasculare. Sindromul metabolic nu este o afecțiune de sine stătătoare, ci un cumul de factori de risc ce predispun la apariția diabetului și bolilor cardiace ischemice (Fig. 1). În medicina veterinară, sindromul metabolic este bine cunoscut și definit la ecvine, însă cercetătorii și medicii abia încep să definească un sindrom similar la câine, denumit variabil sindrom metabolic sau disfuncție metabolică asociată obezității.
Prin incidența crescută a obezității, crește frecvența sindromului metabolic la om.

Prevalența sindromului metabolic la om diferă în funcție de aria geografică și de vârstă. Prevalența în populația mexicană (peste 65 ani) a fost $72,9 \%$, iar componentele au avut următoarea dispunere: hipertensiune $92,4 \%$, hipertrigliceridemie $77,8 \%$, HDL colesterol scăzut $77,1 \%$, hiperglicemie $71,1 \%$, obezitate centrală $65,4 \%$ (2).

La câine putem, de asemenea, discuta despre o „epidemie a obezității“ în țările dezvoltate, în care animalele de companie au un stil de 
viață asemănător cu al proprietarului. Și la animalele de companie obezitatea se datorează unui complex de factori, aceștia incluzând dieta, nivelul de activitate fizic, factori de comportament, factori genetici, factori socio-economici, factori de mediu, metabolici și factori depen- denți de microbiom (3). În cele ce urmează, vom analiza literatura de specialitate, urmărind comparativ omul și câinele.

Federația Internațională pentru Diabet definește criteriile de diagnostic ale sindromului metabolic astfel: prezența obezității centrale și a

(a)

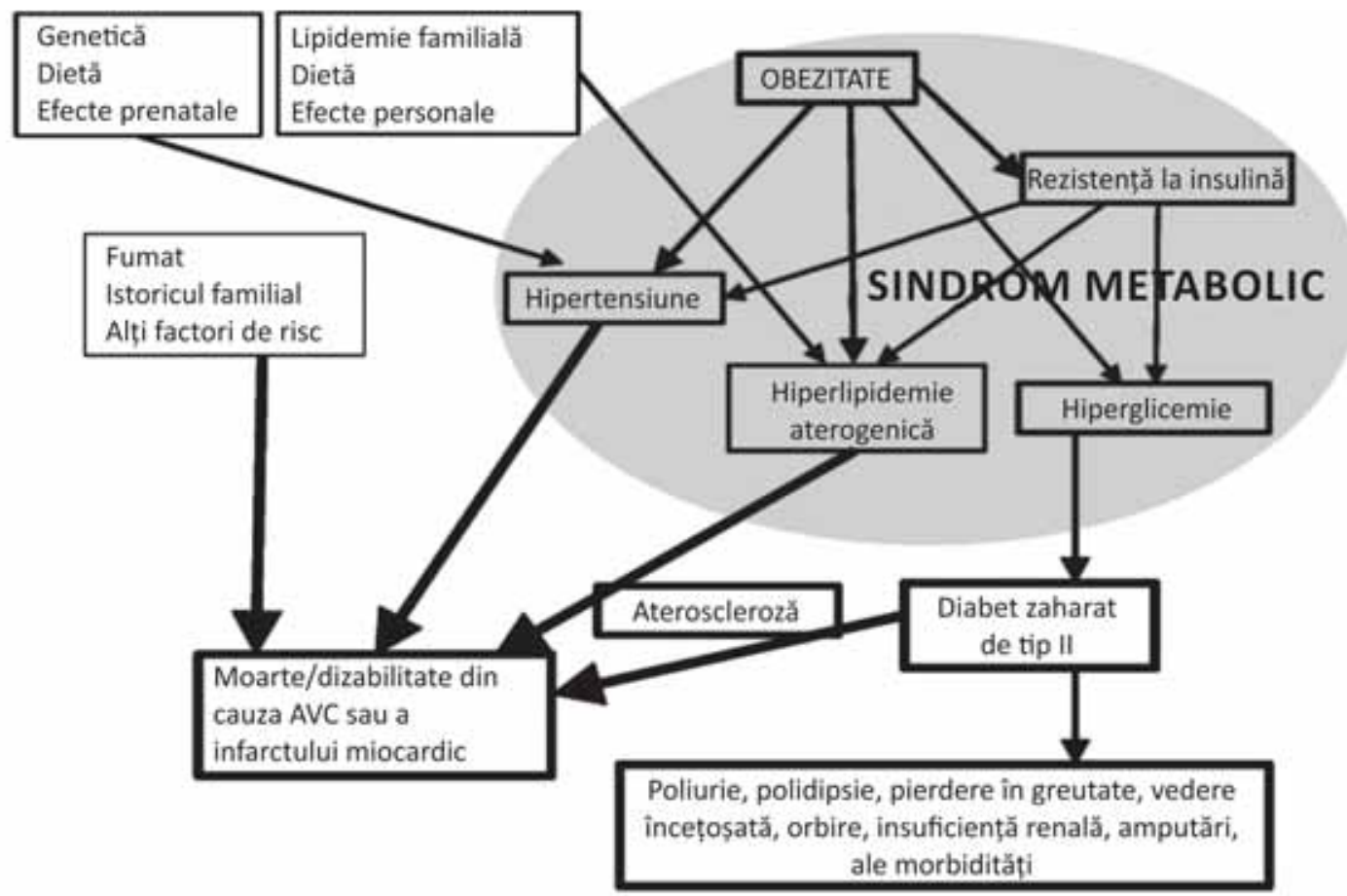

(b)

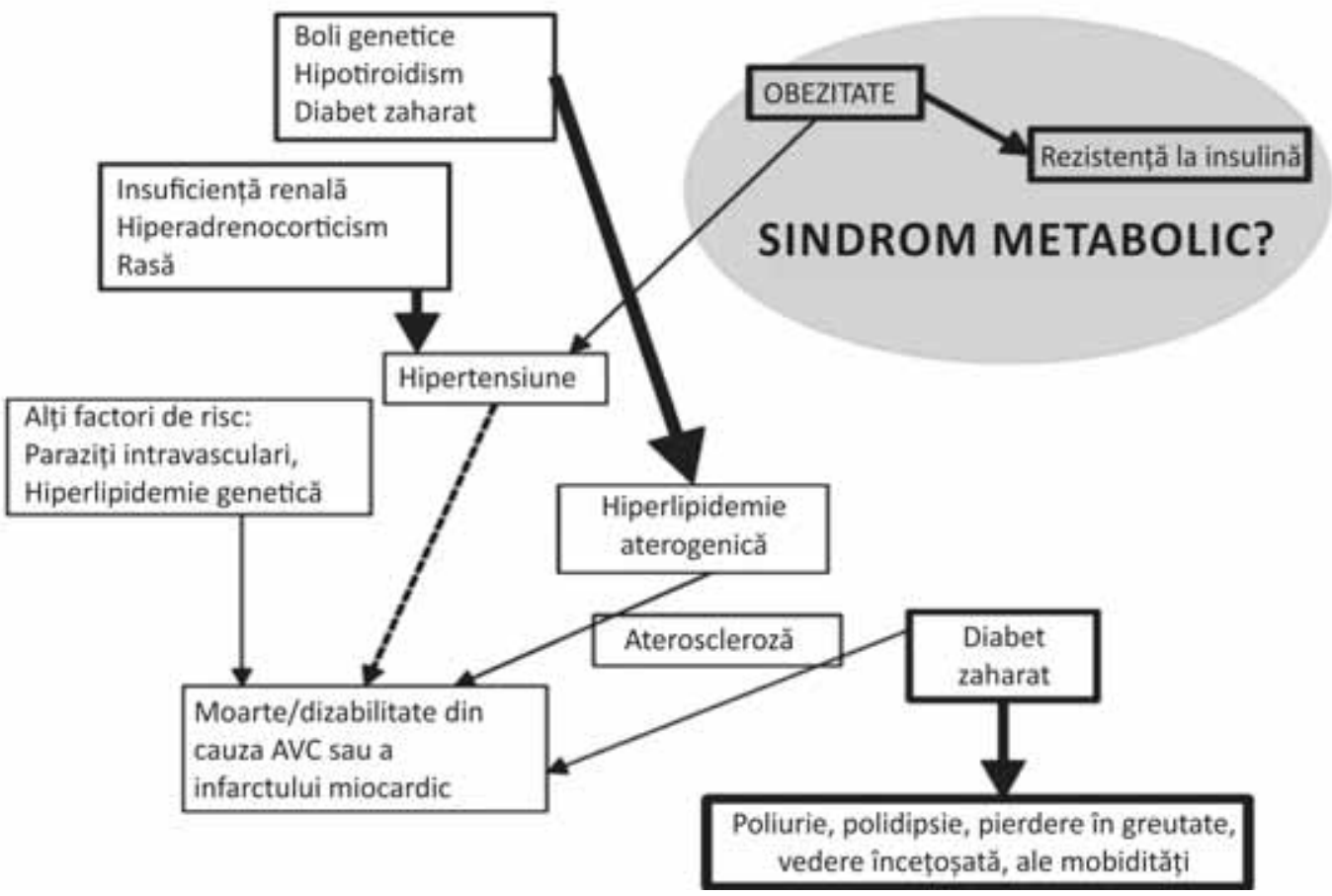

FIGURA 1. (a) Diagrama simplificată a componentelor sindromului metabolic (SM) şi a relației acestuia cu accidentul vascular cerebral (AVC) şi infarctul miocardic, cele mai frecvente cauze ale morții la om. (b) Elemente ale SM ce pot fi identificate la câine, specie la care nu au putut fi demonstrate aceleași corelații între diferitele etiologii și entități patologice. Săgețile îngroşate indică efecte puternice, cele subțiri indică efecte rare sau minore. Săgețile discontinue reprezintă efecte ce nu au fost demonstrate încă. Chenarele groase indică afecțiuni comune, iar cele subțiri, patologii rare.

După Verkest KR, 2014 (1) 
doi dintre următorii patru factori: nivel sanguin al trigliceridelor crescut $(\geq 150 \mathrm{mg} / \mathrm{dl} \quad(1,7$ $\mathrm{mmol} / \mathrm{l})$ sau tratament specific pentru această modificare biochimică); colesterol HDL scăzut $-<40 \mathrm{mg} / \mathrm{dl}(1,03 \mathrm{mmol} / \mathrm{l})$ la bărbat și $<50 \mathrm{mg} / \mathrm{dl}$ $(1,29 \mathrm{mmol} / \mathrm{l})$ la femei, sau tratament specific pentru reducerea colesterolemiei; tensiune arterială crescută (TA sistolică $\geq 130 \mathrm{~mm} \mathrm{Hg}$ sau diastolică $\geq 85 \mathrm{~mm} \mathrm{Hg}$ sau tratament pentru hipertensiune diagnosticată anterior); glucoză serică sau plasmatică bazală (dupa o perioadă de post de cel puțin 8 ore $) \geq 100 \mathrm{mg} / \mathrm{dl}(5,6 \mathrm{mmol} / \mathrm{l})$ sau diabet zaharat de tip II diagnosticat anterior (4).

Fiecare dintre criteriile de diagnostic are un anumit impact asupra calității vieții (5).

La câine, criteriile propuse pentru încadrarea în sindrom metabolic au fost adaptate după criteriile Federației Internaționale pentru Diabet, incluzând încadrarea într-o categorie de obezitate de 7-9 (utilizând un sistem de evaluare corporală cu 9 trepte (Fig. 2) (6) alături de prezența a minimum doi dintre următorii factori: tensiunea arterială sistolică $>160 \mathrm{mmHg}$, colesterol total $\mathrm{CHOL}>300 \mathrm{mg} / \mathrm{dl}(7,8 \mathrm{mmol} / \mathrm{l})$, trigliceride TG $>200 \mathrm{mg} / \mathrm{dl}(2,3 \mathrm{mmol} / \mathrm{l})$ și glicemia $>100$ $\mathrm{mg} / \mathrm{dl}(5,6 \mathrm{mmol} / \mathrm{l})$ sau diabet zaharat diagnosticat anterior, valori măsurate după o perioadă de post de 8 -12 ore $(1,7,8)$. Alți autori propun alte criterii: $\mathrm{BCS}>3,5$ (folosind un sistem cu 5 trepte) alături de două dintre următoarele: criterii: glicemie $\geq 120 \mathrm{mg} / \mathrm{dl}$, dislipidemie, alaninaminotransferaza ALT $\geq 100 \mathrm{UI} / \mathrm{I}$ și confirmă diagnosticul prin măsurarea insulinemiei $(\geq 2,5$ $\mathrm{ng} / \mathrm{ml}$ ) (9). Dislipidemia este diagnosticată prin prezența a două dintre următoarele trei modifi- cări: TG $\geq 165 \mathrm{mg} / \mathrm{dl}$ sau $\mathrm{CHOL} \geq 200 \mathrm{mg} / \mathrm{dl}$ sau acizi grași neesterificați NEFA $\geq 1,5 \mathrm{mEq} / \mathrm{l}$ (8). Unii autori denumesc echivalentul SM la câine ca disfuncție metabolică asociată obezității (7).

La om, sindromul metabolic cuprinde obezitate centrală, toleranță alterată la glucoză sau diabet, hipertensiune arterială și dislipidemii (3). Criteriul de bază, obezitatea centrală, este definită la om ca fiind circumferința taliei de peste $90 \mathrm{~cm}$ la bărbat și $80 \mathrm{~cm}$ la femeie sau indice de masă corporală $>30 \mathrm{~kg} / \mathrm{m}^{2}(4,10)$. La câine, având în vedere variația genetică și variabilitatea fenotipică, criteriul obezității centrale este înlocuit cu un sistem de evaluare corporală denumit "Body Condition Score" (BCS), cu 9 trepte descrise în detaliu (Fig. 2), de la subponderalitate severă la obezitate morbidă. Determinarea scorului corporal la câine are o importanță deosebită pentru monitorizarea stării de sănătate a câinilor; astfel, acordarea unui scor corporal este utilă pentru a aprecia dacă greutatea câinelui este adecvată în raport cu talia și rasa din care face parte, dacă prezintă și alte afecțiuni subclinice și schimbări ale statusului nutrițional, dacă există modificări ce pot conduce către obezitate sau creșterea ponderală este patologică (12). Tvarijonaviciute et al. au investigat modificările survenite în urma pierderii în greutate la câine și au identificat îmbunătățirea procentului de grăsime în corp, scăderea tensiunii arteriale sistolice, scăderea valorilor lipidelor plasmatice și a insulinemiei, alături de creșterea valorii adiponectinei (7). Din păcate, în practica veterinară curentă nu este fezabilă determinarea valorilor adiponectinei și a insulinei în sânge în scop de monitorizare.

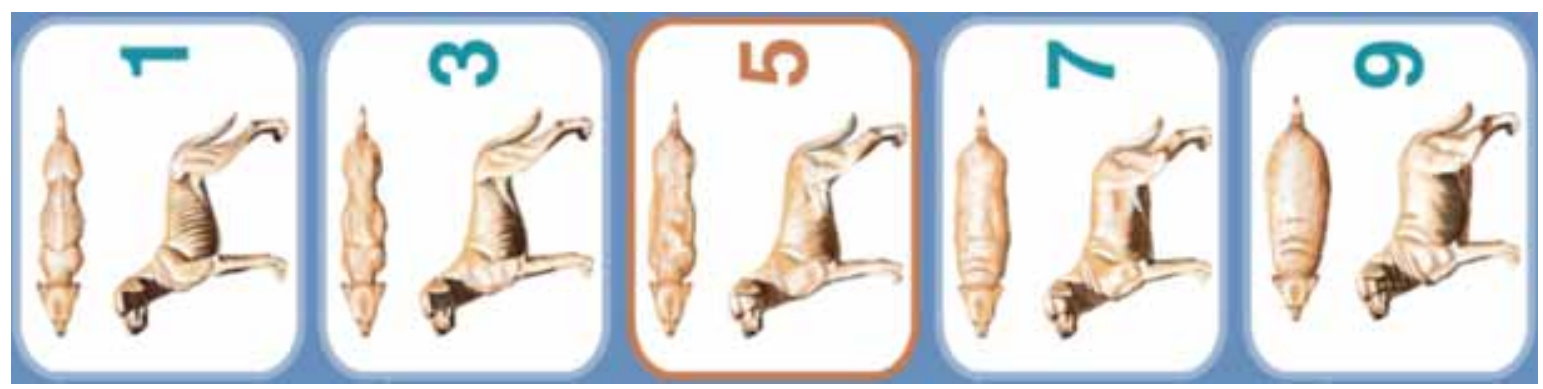

FIGURA 2. Scorul corporal la câine, după Nestlé Purina şi AAHA (6, 11).

$B C S=1$ Coaste, vertebre lombare, oase pelvine şi toate proeminențele osoase evidente de la distanță. Nu se poate observa grăsime corporală; pierderea evidentă a masei musculare. BCS=2 Coastele, vertebrele lombare şi oasele pelvine sunt uşor vizibile; nu se evidențiază o grăsime palpabilă, ci doar unele dovezi ale altor proeminențe osoase. BCS=3 Coaste vizibile, cu reducerea grăsimii. Proeminențele vertebrelor lombare şi ale oaselor pelvine, pierderea evidentă a masei musculare. $B C S=4$ Coaste uşor palpabile, cu un strat minim de grăsime ce le înconjoară, talia evidentă din spate. BCS=5 Coaste uşor palpabile fără grăsime înconjurătoare; talie uşor vizibilă în spatele coastelor; abdomen supt. BCS=6 Coaste palpabile cu o uşoară acoperire cu grăsime. Talia şi abdomenul sunt evidente doar privind din spatele animalului. BCS=7 Coaste palpabile cu dificultate, strat consistent de grăsime înconjurătoare, depozite adipoase evidente în zona lombară şi la baza cozii; talia abia vizibilă. BCS=8 Coatele nu pot fi palpate decât printr-o presiune semnificativă, din cauza stratului abundent de grăsime. Depozite masive de grăsime şi distensie abdominală. BCS=9 Depozite masive de grăsime la nivelul toracelui, gâtului, membrelor şi oaselor pelvine. Distensie abdominală evidentă. 
Hipertensiunea arterială (HTA) este definită ca valori ale tensiunii arteriale sistolice de peste $160 \mathrm{mmHg}$ sau tratament instituit pentru aceasta $(7,4)$ și are la câine, ca și la om, efecte dăunătoare asupra rinichilor (de ex., boală renală progresivă), sistemului cardiovascular (ex. insuficiență cardiacă), ochilor (ex. leziuni retiniene și coroidale) și sistemului nervos central (ex. encefalopatie hipertensivă) $(7,13)$. Spre deosebire de om, la care, în 95\% dintre cazuri, hipertensiunea arterială este esențială sau idiopatică, la câine, aceasta este - de cele mai multe ori - secundară unei alte afecțiuni (14), principala dintre acestea fiind insuficiența renală cronică, alături de hipertiroidism, diabet zaharat, hiperadrenocorticism, feocromocitom și hiperaldosteronism $(14,13)$. Alte cauze sunt administrarea de medicamente care pot crește TA, precum glucocorticozii, ciclosporina, fenilpropanolamina și eritropoietina (14). Studiile realizate până acum au arătat că animalele supraponderale și obeze, prin inflamație cronică și rezistență vasculară periferică determinate de obezitate $(15,16)$, au TA crescută, însă - în majoritatea cazurilor - nu la un nivel manifestat clinic, discutându-se în majoritatea cazurilor de creșteri insesizabile de $5 \mathrm{mmHg}$, dar și de creșteri de peste $20 \mathrm{mmHg}$ (1). Câinii obezi pot avea, ca și oamenii, hipertrofie ventriculară stângă, în special a septumului interventricular, reversibilă prin slăbire $(1,17)$, dar și disfuncție pulmonară, hipertensiune pulmonară și hipertrofie ventriculară dreaptă (16).

Dislipidemiile, definite ca valori sanguine ale trigliceridelor TG $>200 \mathrm{mg} / \mathrm{dl}(2,3 \mathrm{mmol} / \mathrm{l})$ și ale colesterolului total $\mathrm{CHOL}>300 \mathrm{mg} / \mathrm{dl} \quad(7,8$ $\mathrm{mmol} / \mathrm{l})$, figurează ca unic factor sau ca factori multipli ai SM, în funcție de autor $(6,1,7)$; la acestea, se pot adăuga și acizii grași neesterificați NEFA $\geq 1.5 \mathrm{mEq} / \mathrm{l}$ (8). Unele studii diferențiază între colesterolul HDL, LDL și VLDL; la câine, $80 \%$ din colesterolul total se găsește sub formă de colesterol HDL (1). Față de om, la care obezitatea determină o creștere a colesterolului LDL și o scădere a HDL-c, la câinele obez, acestea cresc concomitent, astfel încât poate fi utilizat ca parametru colesterolul total (7). Câinii par să fie mai puțin predispuși la ateroscleroză datorită compoziției lipoproteinelor și a metabolismului acestora, însă, atunci când apare spontan sau este indusă experimental, boala se asociază cel mai frecvent hipercolesterolemiilor determinate de endocrinopatii (de ex., hipotiroidism sau diabet zaharat) (18). Câinii obezi pot prezenta creșteri ale colesterolului (chilomicroni, VLDL și
HDL) și ale trigliceridelor, fie consecutiv unei afecțiuni primare (foarte rar), fie secundar, prin cauze precum alimentația hiperlipidică, hipotiroidismul, diabetul zaharat, pancreatita acută, hiperadrenocorticismul, anorexia sau înfometarea, secundar unor afecțiuni hepatice (colestaza; hepatita cronică), boli renale (ex. sindrom nefrotic) sau administrarea anumitor substanțe (corticosteroizi) $(1,18,19)$.

Hipertrigliceridemia și hipercolesterolemia se asociază neexclusiv cu ateroscleroza, aceasta apărând la căine și în absența acestora și a endocrinopatiilor, printr-un mecanism neelucidat încă $(21,22)$. Într-un studiu retrospectiv asupra a 30 de câini cu ateroscleroză confirmată prin examen histopatologic post-mortem, $77 \%$ dintre indivizi aveau o afecțiune endocrină, iar restul nu prezentau nici un semn al unei astfel de boli, 4/7 având chiar colesterolul seric în limite normale; doar 8 dintre cei 30 erau obezi (21). În același studiu, ateroscleroza a fost înregistrată în diferite organe, însă cu precădere la nivelul arterelor coronare (66\%), al vascularizației glandei tiroide, rinichilor, aortei, splinei și altele (21). Întrucât prevalența aterosclerozei la câine este extrem de redusă, iar obezitatea nu se asociază întotdeauna cu dislipidemii, nu putem identifica aceleași relații de interdeterminare ca în cazul sindromului metabolic la om (Fig. 1). Totuși, putem afirma că afecțiunile cu componentă metabolică, printre ele numărându-se și factori ai SM, pot determina, atunci când depășesc rezistența înnăscută a câinelui, ateroscleroză și dislipidemii. Una dintre cauze este schimbarea stilului de viață cu unul similar stăpânului, la care metabolismul de carnivor nu se poate adapta dincolo de anumite limite.

Hiperglicemia, definită ca valori de peste > $100 \mathrm{mg} / \mathrm{dl}$ (5,6 mmol/l) sau diabet zaharat diagnosticat anterior, este o altă componentă discutabilă a SM în cazul câinelui, pornind chiar de la valoarea glicemiei de $100 \mathrm{mg} / \mathrm{dl}$, care pentru unii autori este cuprinsă în limite fiziologice chiar după o perioadă de înfometare, aceștia preferând să considere hiperglicemie o valoare de peste $120 \mathrm{mg} / \mathrm{dl}$, pe care o fixează ca limită superioară $(7,8)$. Cea mai frecventă formă de diabet la câine este diabetul zaharat de tip I, la momentul diagnosticului majoritatea indivizilor fiind insulino-dependenți. Obezitatea nu poate fi incriminată ca o cauză a diabetului la câine, acesta fiind determinat de un deficit de insulină, ea intervenind însă prin fenomenul rezistenței la insulină ce complică managementul bolii (23). Kolka et al. (24) au realizat un studiu pe câini an- 
esteziați menținuți la o glicemie de 100 mg/dl (normoglicemie) și 120 mg/dl (hiperglicemie moderată). Acestora li s-a inoculat insulină intramuscular într-unul dintre membrele posterioare, celălalt servind drept control, apoi au fost preluate probe de sânge și limfă, observându-se că, în cazul animalelor cu hiperglicemie, difuzia insulinei în spațiul interstițial a fost împiedicată, reducându-se preluarea glucozei în celule prin efectul insulinei, față de animalele normoglicemice, la care valoarea insulinei în limfă la nivelul membrului a crescut (24). Glicemia este crescută în cazul câinilor obezi, atât după 12 ore fără hrană, cât și postprandial, în comparație cu animale normoponderale și în ciuda unei insulinemii mai ridicate (25), însă valorile nu depășesc de cele mai multe ori limita superioară a intervalului fiziologic. Totuși, un studiu realizat pe câini care au fost supuși unei pancreatectomii parțiale a demonstrat că o glicemie susținută de peste $250 \mathrm{mg} / \mathrm{dl}$ are efecte toxice asupra celulelor $\beta$ pancreatice, determinând apariția diabetului zaharat de tip II (25).

În cazul omului, afectarea cutanată asociată frecvent sindromului metabolic este psoriazisul.

Relația dintre psoriazis și sindromul metabolic este, probabil, bidirecțională, cu psoriazisul care favorizează sindromul metabolic și sindromul metabolic care predispune la psoriazis $(26,27)$.

La animale, până acum, au fost doar modele induse de psoriazis, în schimb, alte afecțiuni cutanate care au echivalent în patologia umană pot fi diagnosticate.

Leziunile cutanate în leishmanioza canină (CanaL) sunt diverse, incluzând dermatită exfoliativă (scoame psoriaziforme), ulcerativă, nodulară și papulară (28).

Dermatita atopică afectează pâna la $10 \%$ dintre câini și, asemenea formei umane a bolii, se caracterizează prin prurit și erupții cutanate, putându-se croniciza și având recăderi acute ale manifestărilor cutanate (29).

\section{DISCUTुII}

La om, sindromul metabolic însumează o serie de factori de risc ce predispun la apariția bolii cardiace ischemice și a diabetului, cauze semnificative de deces prin accident vascular. La câine, nu putem însă demonstra aceste corelații și interdependențe în patogeneza acelorași afecțiuni și nu putem identifica un sindrom bine definit, ci, mai degrabă, disfuncții metabolice asociate obezității. Spre deosebire de medicina umană, în medicina veterinară lipsesc posibilitățile de a realiza studii de anvergură la standarde corespunzătoare, iar cercetările suferă din cauza numărului mic de pacienți incluși în studii. Totuși, putem prelua din medicina umană semnalul de alarmă care trebuie tras la identificarea unui pacient ce se află într-una sau mai multe dintre categoriile de risc identificate pentru a-I putea trata și monitoriza în ansamblu, interdisciplinar și nu secvențial. Totodată, din experiența noastră, pacienții canini și felini dezvoltă de multe ori o patologie comună cu a stăpânilor, din cauza condițiilor de viață similare, iar identificarea unei patologii metabolice la unul dintre membrii familiei poate fi un bun prilej de a diagnostica precoce o afecțiune a altuia.

\section{CONCLUZII}

Necesitatea uniformizării criteriilor de diagnostic în sindromul metabolic atât la om, cât și la câine este evidentă. Până la urmă, conceptul de „One world, one health, one medicine" (O lume, o sănătate, o medicină), care evidențiază interdependența dintre mediu, animale și om și pune accent pe nevoile celor dintâi pentru binele celui din urmă, este mult mai palpabil decât ne imaginăm.

Conflict of interest: none declared Financial support: none declared

\section{REFERENCES}

1. Verkest K.R.(2014) Is the metabolic syndrome a useful clinical concept in dogs?A review of the evidence, The Veterinary Journal, Volume 199, Issue 1, January 2014, Pages 24-30

2. María Araceli Ortiz-Rodríguez, Lucía Yáñez-Velascob, Alessandra Carnevale et al. Prevalence of metabolic syndrome among elderly Mexicans. Archives of 254
Gerontology and Geriatrics. 2017; 73: 288-293.

3. Ahima R.S. (Ed.) (2016) Metabolic Syndrome, A Comprehensive Textbook, Springer International Publishing, Switzerland

4. ${ }^{* * * *}(2006)$ The IDF consensus worldwide definition of the Metabolic Syndrome, International Diabetes Federation
5. Stănescu A.M.A., Matei A., Grăjdeanu I.V. et al. Multipli factori de interes în managementul psoriazisului şi comorbidităţilor asociate. Practica Medicală. 2016; 11: 49-52.

6. ${ }^{* \star * \star \star \star}$, Nestlé Purina Pet Care Center, preluat la 10 noiembrie 2017 de pe www. thedrakecenter.com/services/pets/blog/ fit-or-fat-your-pets-body-condition-score-bcs 
7. Tvarijonaviciute A., Ceron J.J., Holden S.L., Cuthbertson D.J., Biourge V., Morris P.J., German A.J. Obesity-related metabolic dysfunction in dogs: a comparison with human metabolic syndrome, BMC Veterinary Research, 2012, Volume 8, Number 1, Page 1

8. Cardoso M.J.L., Fagnani R., Zaghi C. et al. (2016) Blood Pressure, Serum Glucose, Cholesterol, and Triglycerides in Dogs with Different Body Scores, Veterinary Medicine International, vol. 2016, Article ID 8675283, 7 pages, 2016. doi:10.1155/2016/8675283

9. Kawasumi K., Suzuki T., Fujiwara M., Mori N., Yamamoto I., Kawasumi T.A. (2012) New Criteria for Canine Metabolic Syndrome in Japan, Journal of Animal and Veterinary Advances, 11: 4005-4007

10. Alberti K.G.M.M., Eckel R.H, Grundy S.M., Zimmet P.Z., Cleeman J.I., Donato K.A., Fruchart J.C., James P.T., Loria C.M., Smith S.C. (2009) Harmonizing the Metabolic Syndrome (A Joint Interim Statement of the International Diabetes Federation Task Force on Epidemiology and Prevention; National Heart, Lung, and Blood Institute; American Heart Association; World Heart Federation;International Atherosclerosis Society; and International Association for the Study of Obesity), Circulation, 2009;120:1640-1645

11. $13 .{ }^{* * *}$, American Animal Hospital Association, https://www.aaha.org/ public_documents/professional/guidelines/ weightmgmt_bodyconditionscoring.pdf, accesat la 15.11.2017

12. Sanderson Sherry Lynn (2010), Body Condition Score Techniques for Dogs, Procedures Pro Nutrition, NAVC Clinician's Brief, March 2010, pg. 13-16

13. Bonagura J.D., Twedt D.C. (2014) Kirk's Current Veterinary Therapy XV, 1st Edition, Saunders Elsevier, SUA
14. Reece W.O. (ed.) (2015) Dukes' Physiology of Domestic Animals, $13^{\text {th }}$ edition, John Wiley \& Sons, Inc., Wiley-Blackwell, SUA

15. Monteiro R., Azevedo I. (2010) Chronic Inflammation in Obesity and the Metabolic Syndrome, Hindawi Publishing Corporation, Mediators of Inflammation Volume 2010, Article ID 289645, 10 pages, doi:10.1155/2010/289645

16. Vachharajani V., Granger D.N. (2009) Adipose tissue: A motor for the inflammation associated with obesity, IUBMB Life. 2009 April ; 61(4): 424-430. doi:10.1002/iub.169

17. Tropf M., Nelson O.L., Lee P.M., Weng H.Y. (2017) Cardiac and Metabolic Variables in Obese Dogs, J Vet Intern Med 2017; 31: 1000-1007

18. Xenoulis P.G., Steiner J.M. (2008) Lipid metabolism and hyperlipidemia in dogs, The Veterinary Journal 183 (2010) 12-21

19. Watson T.D.G., Barrie J. (1993) Lipoprotein metabolism and hyperlipidaemia in the dog and cat, Journal of Small Animal Practice (1993) 34, 479-487

20. Hess R.S., Kass P.H., Van Winkle T.J. (2003) Association between Diabetes Mellitus, Hypothyroidism or Hyperadrenocorticism, and Atherosclerosis in Dogs, J Vet Intern Med 2003;17:489-494

21. Kagawa Y., Hirayama K., Uchida E., Izumisawa Y., Yamaguchi M., Kotani T., Niiyama M., Yoshino T., Taniyama H. (1998) Systemic Atherosclerosis in Dogs: Histopathological and Immunohistochemical Studies of Atherosclerotic Lesions, Journal of Comparative Pathology Volume 118, Issue 3, April 1998, Pages 195-206

22. Chandler M., Cunningham S., Lund E.M., Khannax C., Naramore R., Patel A., Day M.J. (2017) Obesity and Associated Comorbidities in People and Companion
Animals: A One Health Perspective, J. Comp. Path. 2017, Vol. 156, 296e309

23. Kolka C.M., Castro A.V.B., Kirkman E.L., Bergman R.L. (2015) Modest hyperglycemia prevents interstitial dispersion of insulin in skeletal muscle, Metabolism, 2015 February; 64(2): 330-337, doi:10.1016/j. metabol.2014.10.036

24. Verkest K.R., Rand J.S., Fleeman L.M., Morton J.M. (2012) Spontaneously obese dogs exhibit greater postprandial glucose, triglyceride, and insulin concentrations than lean dogs, Domestic Animal Endocrinology 42 (2012) 103-112

25. Imamura T., Koffler M., Helderman J.H., Prince D., Thirlby R., Inman L., Unger R.H. (1988) Severe diabetes induced in subtotally depancreatized dogs by sustained hyperglycemia, Diabetes 1988;37:600-9

26. Stănescu A.M.A, Matei A., Grăjdeanu I.V. et al. Asocierea între psoriazis şi sindrom metabolic, corelată cu deficitul vitaminei D în ambele afecţiuni. Revista Medicală Română. 2016; 1: 81-85.

27. Stănescu A.M.A. Psoriazisul. În: Dumitru M. Esenţialul în medicina de familie, ediţia 3. Amaltea, Bucureşti 2016: 384-388.

28. Colombo S., Abramo F., Borio S. et al. Pustular dermatitis in dogs affected by leishmaniosis: 22 cases. Vet Dermatol, 2016; 27: 9-e4. doi:10.1111/vde.12274

29. D. Ka, G. Marignac, L. Desquilbet et al. Association between passive smoking and atopic dermatitis in dogs. Food and Chemical Toxicology. 2014; 66: 329-333 https://doi.org/10.1016/j.fct.2014.01.015 